\title{
Erratum zu: Die Formierung einer medizinischen Disziplin: Psychiatrie in Österreich im 19. Jahrhundert
}

\author{
E. Gabriel
}

Online publiziert: 17. November 2020

(C) Springer-Verlag GmbH Austria, ein Teil von Springer Nature 2020

\section{Erratum zu:}

\section{Neuropsychiatr 2020}

https://doi.org/10.1007/s40211-020-00357-7

Die Originalversion dieses Artikels, veröffentlicht am 19. August 2020, enthielt leider einen Fehler.

Zwei Referenzen waren leider inkorrekt. Die korrekten Referenzen [32,34] sind unten angegeben.

\section{Literatur}

32. Krafft-Ebing R. Frh. v. Lehrbuch der Psychiatrie auf klinischer Grundlage. Stuttgart:Enke, 1879 (7.Aufl. 1903)

34. Meynert Th. Psychiatrie. KLinik der Erkrankungen des Vorderhrins, begründet auf dessen Bau, Leistungen und Ernährung. Wien: Braumüller, 1884 (Erste Hälfte)

Hinweis des Verlags Der Verlag bleibt in Hinblick auf geografische Zuordnungen und Gebietsbezeichnungen in veröffentlichten Karten und Institutsadressen neutral.

Die Online-Version des Originalartikels ist unter https://doi. org/10.1007/s40211-020-00357-7 zu finden.

Univ. Prof. Dr. E. Gabriel ( $₫)$

Wien, Österreich

eberhard.gabriel@gmx.at 